\title{
Cloning and characterization of a V-ATPase subunit C from the American visceral leishmaniasis vector Lutzomyia longipalpis modulated during development and blood ingestion
}

\author{
JM Ramalho-Ortigão, AN Pitaluga, EL Telleria, C Marques, AA Souza*, \\ YM Traub-Cseko/ ${ }^{+}$
}

\begin{abstract}
Laboratório de Biologia Molecular de Tripanossomatídios e Flebotomíneos, Departamento de Bioquímica e Biologia Molecular, Instituto Oswaldo Cruz-Fiocruz, Av. Brasil 4365, 21045-900 Rio de Janeiro, RJ, Brasil *Instituto Evandro Chagas, Seção de Parasitologia, Belém, PA, Brasil
\end{abstract}

Visceral leishmaniasis (VL) is a serious tropical disease that affects approximately 500 thousand people worldwide every year. In the Americas, VL is caused by the parasite Leishmania (Leishmania) infantum chagasi mainly transmitted by the bite of the sand fly vector Lutzomyia longipalpis. Despite recent advances in the study of interaction between Leishmania and sand flies, very little is known about sand fly protein expression profiles. Understanding how the expression of proteins may be affected by blood feeding and/or presence of parasite in the vector's midgut might allow us to devise new strategies for controlling the spread of leishmaniasis. In this work, we report the characterization of a vacuolar ATPase subunit $C$ from L. longipalpis by screening of a midgut cDNA library with a 220 bp fragment identified by means of differential display reverse transcriptasepolymerase chain reaction analysis. The expression of the gene varies along insect development and is upregulated in males and bloodfed $\mathrm{L}$. longipalpis, compared to unfed flies.

Key words: Lutzomyia longipalpis - V-ATPase - metacyclogenesis - differential expression

Leishmaniasis is an important public health problem in the whole world, with approximately 350 million people living in risk areas, 12 million people infected, and 2 to 3 million new cases every year. More than $90 \%$ of all cases of visceral leishmaniasis (VL) in the New World are in Brazil, with recent epidemic outbreaks even in urban areas (Antunes-Uchoa et al. 2001, Gontijo et al. 2002, Lainson \& Rangel 2005). Lutzomyia longipalpis is the principal vector for Leishmania infantum chagasi-caused VL (Bauzer et al. 2007).

Molecular studies of disease transmitting vectors have led to the discovery of several molecules that hold promise in the development of new approaches to fight pathogen transmission. Great advances have been obtained mostly in malaria transmitting mosquitoes: the complete genome of Anopheles gambiae was published (Holt et al. 2002), and transgenic insects were obtained (reviewed in Marrelli et al. 2006). Unfortunately, however, the same cannot be said for sand flies, where similar types of studies are still incipient. Such a lack of information is even more impressive in regards to the

Financial support: Papes IV-Fiocruz, IOC-Fiocruz

${ }^{+}$Corresponding author: ytraub@ioc.fiocruz.br

JMR-O current address: Department of Biological Sciences, University of Notre Dame, 243 Galvin Life Sciences Center, Notre Dame, IN 46556, US

Received 8 December 2006

Accepted 2 April 2007
American visceral leishmaniasis vector, $L$. longipalpis. Apart from the characterization of salivary gland genes (Charlab et al. 1999, Anderson et al. 2006), some recent work has focused on the sequencing of ESTs (RamalhoOrtigão et al. 2001, Dillon et al. 2006) and the identification of a chitinase potentially involved in the biogenesis of the peritrophic matrix (Ramalho-Ortigão \& Traub-Cseko 2003, Ramalho-Ortigão et al. 2005). Other than that, there is virtually no information regarding gene expression profiles in the midgut of this vector.

Our group is investigating patterns of gene expression in L. longipalpis upon blood feeding and/or infection with Leishmania. Our approach relied initially on differential display reverse transcriptase polymerase chain reaction (DDRT-PCR) through which several cDNAs of interest were identified, including some that appear to be expressed exclusively in the midgut of $L$. longipalpis (Ramalho-Ortigão et al. 2001, RamalhoOrtigão \& Traub-Cseko 2003). DDRT-PCR has also been successfully used in the characterization of many mosquito tissue-specific cDNAs, including an A. gambiae midgut-specific V-ATPase (Dimopoulos et al. 1996).

V-ATPase, one of the most fundamental enzymes in nature, energizes a wide variety of organelles and membranes in organisms ranging from insects to higher vertebrates (Nelson 2003). They consist of two large multimeric domains (a membrane spanning and an intracellular), each of which composed by several subunits (Forgac 1989). Such proteins function as proton $(\mathrm{H}+)$ pumps, having the ability to stimulate acidification of cytoplasm in a number of cells. They promote the acidification of the midgut lumen in Bombyx mori (Wieczorek et al. $2000)$ and were identified and characterized in the mosquitoes Culex quinquefasciatus (Fillipova et al. 1998), 
A. gambiae (Dimopoulos et al. 1996), and Aedes aegypti (Gill et al. 1998, Zhuang et al. 1999, Weng et al. 2003). Additionally, Plasmodium gallinaceum ookinetes were shown to selectively invade $A$. aegypti midgut cells in the vicinity of cells expressing high levels of V-ATPase (Cociancich et al. 1999). Later work showed that in A. stephensi, midgut invasion by $P$. berghei preferentially occurs through cells expressing low levels of V-ATPase (Han et al. 2000). Also, V-ATPases seem to have a role in gregarine infection of A. albopictus (Huang et al. 2006).

Using DDRT-PCR we have identified a cDNA for VATPase subunit $\mathrm{C}$ from Leishmania infected L. longipalpis RNA (Ramalho-Ortigão et al. 2001). In this work, we report the characterization of a full length cDNA coding for this V-ATPase subunit C of L. longipalpis isolated from a midgut expression library established with RNA isolated $6 \mathrm{~h}$ after a blood meal. The cDNA shows a high degree of identity with its counterparts identified in many insects including the mosquito vectors $A$. gambiae and A. aegypti, Drosophila melanogaster, Apis mellifera, and the lepidopterans B. mori and Manduca sexta. This cDNA is up-regulated in the midgut of blood fed L. longipalpis, and has a modulated expression during insect development.

In sand flies, acidification of the midgut following digestion of the blood meal has been incriminated as one of the mechanisms inducing metacyclogenesis of Leishmania and parasite migration towards the foregut (Gontijo et al. 1998), which are fundamental events for subsequent infection of vertebrates. A potential role for VATPase in this process remains to be assessed.

\section{MATERIALS AND METHODS}

Sand flies - Sand flies were originally captured at Santarém (Northern Brazil) and maintained in colony at the Evandro Chagas Institute, Belém.

Infection with L. i. chagasi amastigotes was done with parasites harvested from hamster-infected spleen, homogenized in blood (approximately $10^{6} / \mathrm{ml}$ ) and fed to L. longipalpis adult females using one-day old chick skin membrane. Fully engorged females were dissected 72 and $96 \mathrm{~h}$ after feeding and checked for Leishmania in the midgut. Infected or non-infected insects were used for RNA extraction with Trizol ${ }^{\mathrm{TM}}$ (Life Technologies, Grand Island, NY, US) according to instructions.

DDRT-PCR - RNA purification and DDRT-PCR were performed as described in Ramalho-Ortigão et al. (2001). A differentially amplified band was cloned into pCDNA3 and sequenced. This 220bp cDNA was shown to be similar to V-ATPases of different sources and subsequently used as probe for the detection a complete cDNA from an expression library.

Expression libraries - Total RNA (100-200 ng) purified from midguts dissected $6 \mathrm{~h}$ after blood feeding were used for synthesis of a cDNA library with the $\lambda$ ZAP kit from Stratagene (US), following manufacturer's instructions. The original library was amplified (Sambrook et al. 1989) and the supernatant containing $10^{10} \mathrm{pfu}$ (plaque forming units)/ $\mathrm{ml}$ used to transfect freshly grown XL1blue cells (Stra- tagene, US). Plaques were blotted onto nylon membranes, treated as described (Sambrook et al. 1989), and hybridized to the $220 \mathrm{pb}$ V-ATPase cDNA fragment radioactively labeled using an Amersham-Pharmacia (US) Random Priming kit according to manufacturer's protocol. Blots were washed $\left(3 \times 0.1 \%\right.$ SSC- $0.2 \mathrm{XSSC}$ at $\left.50^{\circ} \mathrm{C}\right)$ and exposed to $\mathrm{X}$-ray film. Positive plaques were picked, transferred to SM buffer, and re-plated for a second round of screening. Finally, positive plaques were used for excision of the pBluescript plasmid and sequenced at the PDTIS/Fiocruz sequencing platform, in an Applied Biosystems 3730 DNA analyzer.

$R T$-PCR - Total RNA was extracted with Trizol reagent according to manufacturer's protocol from groups of 20 fully engorged females at 2, 6, 12, 24, 48, 72, 96, and $168 \mathrm{~h}$ after blood feeding, or $72 \mathrm{~h}$ after artificial $L$. $i$. chagasi infection. Total RNA also was extracted from unfed females $(0 \mathrm{~h})$, males, eggs, the four larval stages, and pupae. Up to $5 \mu \mathrm{g}$ of total RNA from each time point was used for 1st strand cDNA synthesis, performed with the First-Strand cDNA Synthesis kit (Amersham). Each cDNA was amplified during PCR reactions containing $0.8 \mu \mathrm{M}$ of each specific primer set in a $25 \mu \mathrm{l}$ reaction. PCR was carried out using the following conditions: $96^{\circ} \mathrm{C} / 3 \mathrm{~min}$, followed by 35 cycles at $96^{\circ} \mathrm{C} / 30 \mathrm{~s}, 57^{\circ} \mathrm{C} /$ $45 \mathrm{~s}$, and $72^{\circ} \mathrm{C} / 45 \mathrm{~s}$, and a final extension of $72^{\circ} \mathrm{C} / 5$ min. The oligonucleotides for V-ATPase were: LIV ATPase-F 5' GTC AGC CTA CAA CAG CCT CAA 3' and LIVATPase-R 5'AGT TTA CGG GCA ATC CAT ACC 3'. As constitutive expression control histone primers were used: His-F 5' GAAAAG CAG GCAAAG ACT CC 3 ' and His-R 5' GAA GGA TGG GTG GAA AGA AG 3'. PCR products were separated in $2 \%$ ethidium bromide-stained agarose gels.

Multiple alignment - Using BLAST search for similarity in GenBank, several V-ATPase sequences from different insects were identified and aligned with ClustalW. V-ATPase sequences used for the alignment were: $B$. mori (ABD36144.1); M. sexta (CAB55498.1); A. mellifera (XP_395359.3); D. melanogaster (AAB62571.1); A. aegypti (ABF18462.1); A. gambiae (XP_556516.1). The output format of ClustalW was submitted to BOX SHADE program to generate the alignment figure.

Phylogenetic tree - A phylogenetic tree was obtained from the V-ATPase multiple alignment (ClustalW) from different insects (B. mori, M. sexta, A. mellifera, D. melanogaster, A. aegypti, A. gambiae) using MEGA3 software. The phylogeny test used was the Neighbor-joining that was carried out with Poisson correction and bootstrap with 10,000 replications.

Southern blot - Genomic DNA was extracted from adult insects using Genomic Prep Cell and Tissue DNA Isolation Kit (Amersham-Pharmacia) according to manufacturer's instructions. DNA $(5 \mu \mathrm{g})$ was digested with the following enzymes: BamHI, BglII, EcoRI, HindIII, PvuII, PstI, and SalI, according to manufacturer's instructions. DNA was separated on $0.8 \%$ agarose gel, transferred to nylon membrane and hybridized to a $220 \mathrm{bp}$ V-ATPase fragment previously identified by DDRT-PCR (Ramalho-Ortigão et al. 2001) labelled with $\alpha^{32} \mathrm{P}$-dCTP using Megaprime DNA Labelling System 
(Amersham Life Science, US). Hybridization was done for $1 \mathrm{~h}$ with QuickHyb solution (Stratagene) at $60^{\circ} \mathrm{C}$, blots were washed three times, $20 \mathrm{~min}$ each, with $0.5 \%$ SDS-0.5XSSC (Sambrook et al. 1989) at $56^{\circ} \mathrm{C}$ and exposed to film (X-OMAT Kodak, US) for $48 \mathrm{~h}$ at $-70^{\circ} \mathrm{C}$.

\section{RESULTS}

Cloning of the V-ATPase subunit C from L. longipalpis - We have identified and sequenced a cDNA (Fig. 1), coding for the subunit $C$ from the sand fly $L$. longipalpis $\mathrm{V} 1$ domain of V-ATPase, by screening a midgut expression library established with RNA purified from flies dissected $6 \mathrm{~h}$ after blood feeding. Analysis of this cDNA revealed a high degree of similarity with many different V-ATPase subunits $C$, specially the ones from $A$. gambiae, A. aegypti, A. mellifera, D. melanogaster, $B$. mori, and M. sexta (Fig. 2). Subsequent analysis of the putative protein coded by this cDNA showed biochemical characteristics similar to those of its counterparts from the afore mentioned insects: putative isoeletric point (pI) of near 8.0, an estimated deduced protein molecular weight (MW) of 40kDa and a hydrophobicity/ hydrophilicity profile that indicates a cytoplasmic location for the protein (i.e. highly hydrophilic) (not shown).

Multiple alignment - Multiple alignment of the amino acid sequences from different insects and from the deduced L. longipalpis sequence demonstrates a well conserved protein (Fig. 2). There are several single amino acids differences among the sequences analyzed. Interestingly, the A. gambiae sequence has a large insertion absent in the other insects, and a small polymorphic site on the $\mathrm{C}$ terminus of the proteins. The vacuolar ATPase subunit $\mathrm{C}$ domain occupied almost the entire sequence.

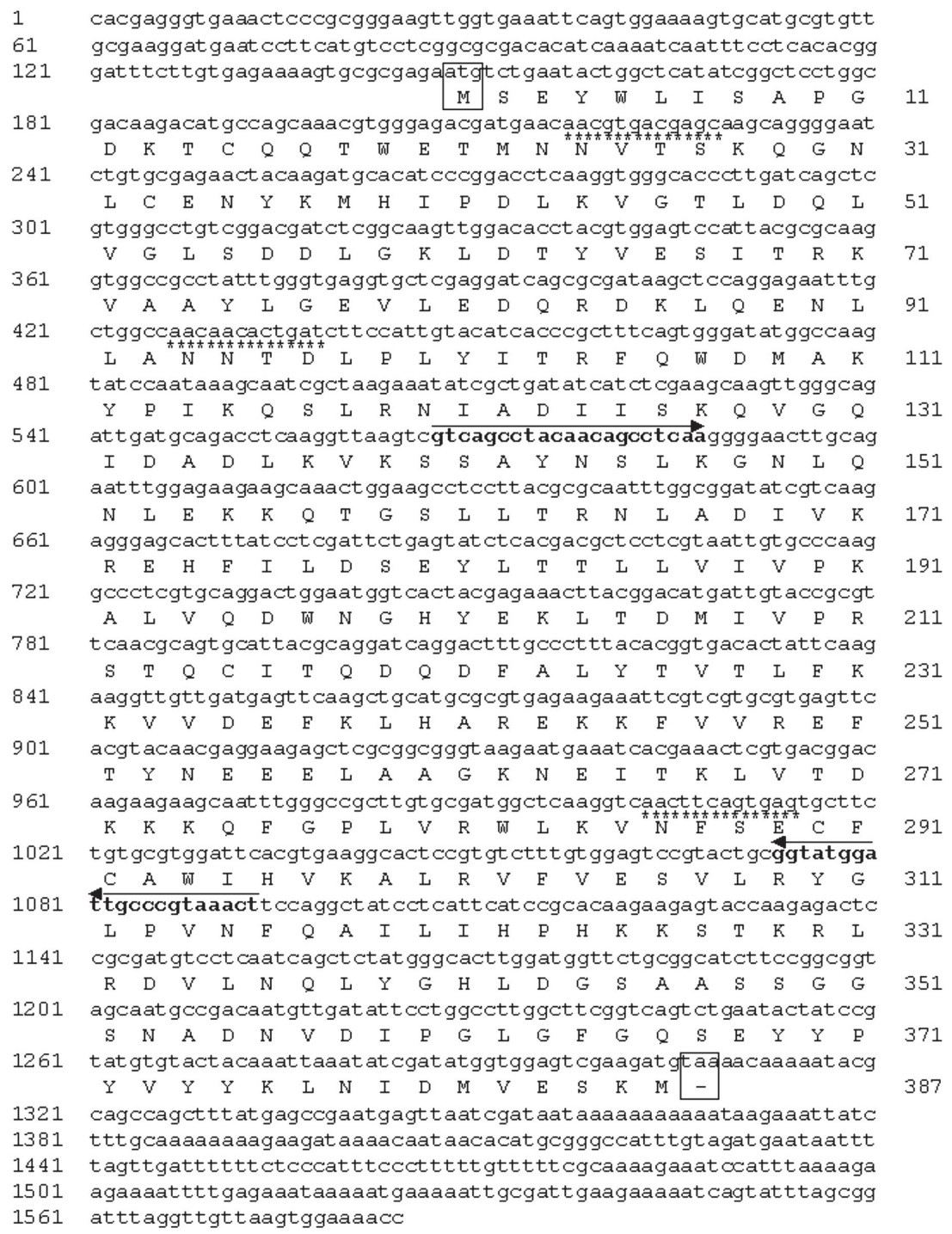

Fig. 1: sequence of V-ATPase cDNA. Arrows and bold letters indicate oligonucleotides used on reverse transcription-polymerase chain reaction experiments; numbers on the left side indicate nucleotide sequence length and on the right side indicate amino acid sequence length; black rectangles indicate start and stop codons; N-glycosylation sites are marked with asterisks (amino acid residues 24-27, 94-97, 286-289). The sequence has the accession number EF156436. 


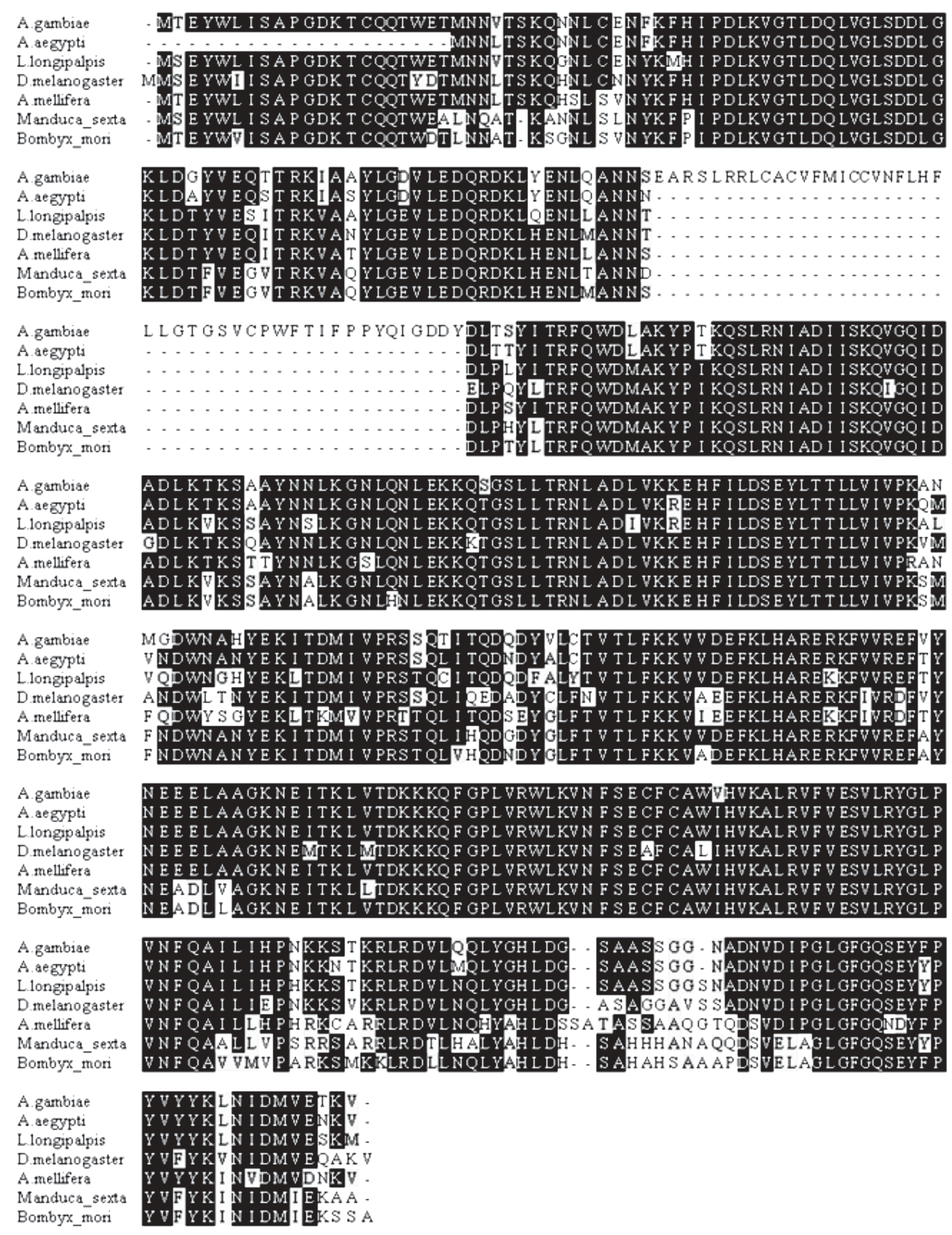

Fig. 2: multiple alignment of V-ATPase protein sequences from several insects. The alignment was built using the ClustalW (http://www.ebi.ac.uk/ clustalw/) and the presentation was made using BOXSHADE (http://bioweb.pasteur.fr/seqanal/interfaces/boxshade.html).

Phylogenetic tree - The molecular evolution of VATPase genes demonstrates a high level of conservation and a correlation with the taxonomy of the selected species (Fig. 3). The tree shows two main groups, the first one represented by the order Lepidoptera (B. mori, $M$. sexta) and the second by Hymenoptera and Diptera orders. Within Diptera it is possible to distinguish another division at the suborder level, the Brachycera (D. melanogaster) being separated from the Nematocera species (L. longipalpis, A. aegypti, A. gambiae).

Southern blot - Genomic DNA of L. longipalpis digested with various restriction enzymes and hybridized to a fragment of the VATPase cDNA showed a pattern of hybridization compatible with one or two genes (Fig. 5). The hybridization to the PvuII digest originates a large double band, which might be explained by the presence of two gene copies, or by a slight size difference of the gene alleles. We have previously found a size difference of chitinase alleles in L. longipalpis (unpublished results).

$R T$-PCR - Fig. 4A shows the results of RT-PCR using cDNA prepared from RNAs extracted from $L$. longipalpis in different stages of development, namely eggs, larvae from the first (L1), second (L2), third (L3), and fourth (L4) instar, pupae, and male and female adults fed on 


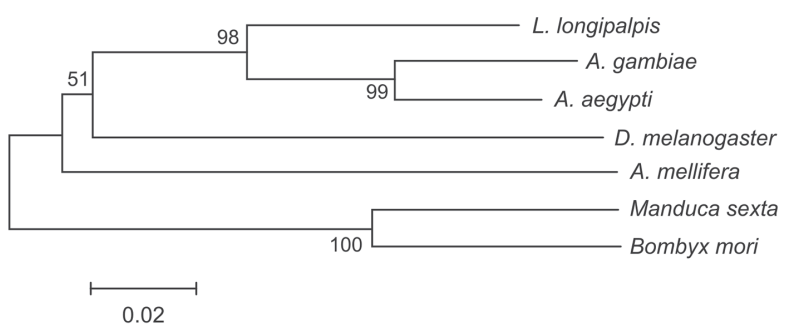

Fig. 3: phylogenetic analysis of V-ATPase. A phylogenetic tree was constructed using Mega3 (Kumar et al. 2004). The tree was built using the Neighbor-Joining (NJ) with 10,000 replications, bootstrap.

A

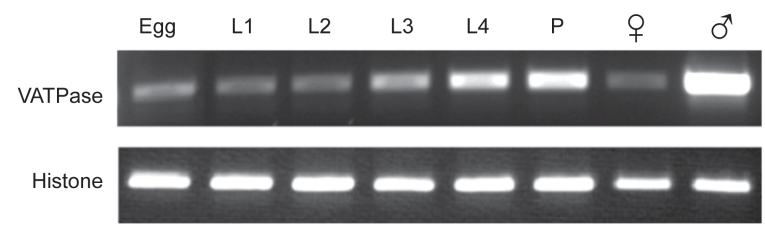

B

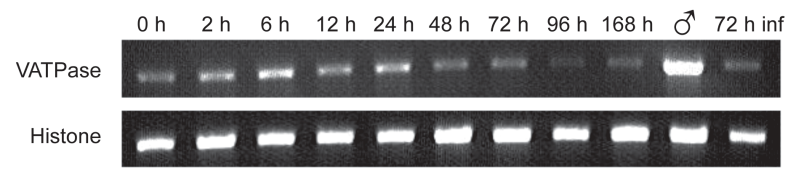

Fig. 4: expression pattern of V-ATPase and histone from developmental stages and blood-fed females of Lutzomyia longipalpis. A: Egg, 1st instar larvae (L1), 2nd instar larvae (L2), 3rd instar larvae (L3), 4th instar larvae (L4), pupae (P), female ( $(+)$ and male ( $\left.\sigma^{\prime}\right)$; B: non-fed females ( $0 \mathrm{~h}$ ), blood fed females (time after blood meal); 2, 6, 12, 24, 48, 72, 96, $168 \mathrm{~h}$, male ( $\delta^{7}$ ) and female ( $+72 \mathrm{~h}$ after infected (L. i. chagasi) blood meal ( $72 \mathrm{~h} \mathrm{inf).}$

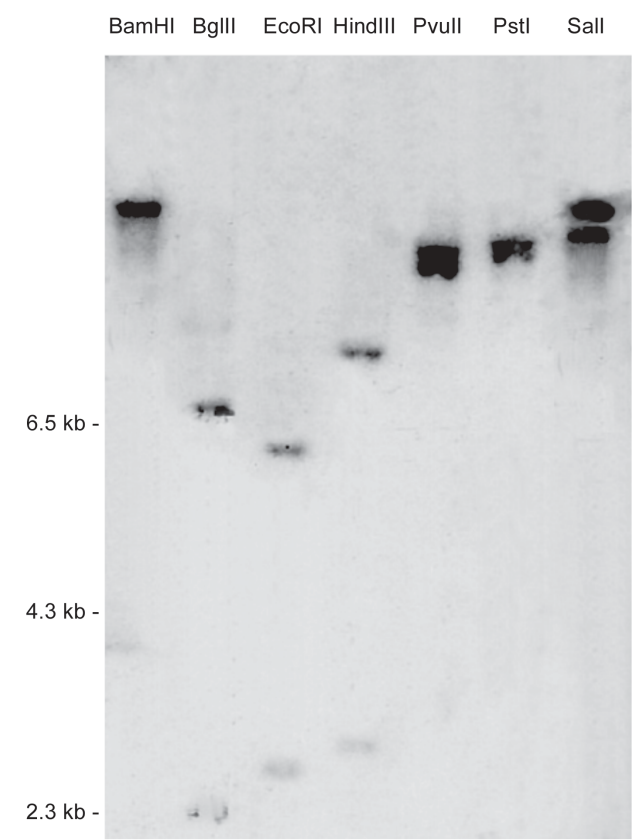

Fig. 5: Southern blot from Lutzomyia longipalpis genomic DNA. DNA was digested with BamHI, BgIII, EcoRI, HindIII, PvuII, PstI, and SalI, and hybridized with a cloned fragment of V-ATPase cDNA probe. Molecular weight marker $\lambda$-HindIII fragments are shown on the left side. sugar. There is a low level of V-ATPase expression in eggs, followed by a slight decrease of expression in L1 larvae and a gradual increase in expression up to pupae. In non-blood fed, the highest expression is found in adult males. In Fig. 4B the expression of V-ATPase was investigated in relation to blood feeding. An increase in VATPase expression was detected as early as $2 \mathrm{~h}$ post blood meal (PBM), continuing up to $24 \mathrm{~h}$ PBM. From the apparent peak at $24 \mathrm{~h} \mathrm{PBM}$, expression of V-ATPase was down regulated beginning at $48 \mathrm{~h}$ PBM and by $96 \mathrm{~h}$ PBM the expression reached its lowest levels. The expression levels at $72 \mathrm{~h}$ PBM appear to be equivalent to what was detected for L1 larvae. Additionally, no difference in V-ATPase expression was detected when we compared un-infected versus infected blood feeds, $72 \mathrm{~h}$ following a blood meal.

\section{DISCUSSION}

V-ATPases are heteromeric proteins that, in general, function as proton pumps (reviewed in Harvey \& Nelson 1992). These enzymes, found in all eukaryotes, are composed of catalytic and transmembrane spanning domains, and possess a broad range of biological functions (Merzendorfer et al. 1997, Forgac 1998, Nelson 2003). In insects V-ATPases are able to perform roles such as membrane energization (Klein 1992) and acidification of cellular compartments or even whole insect's midgut (Jäger et al. 1992, Wieckzorek et al. 1996). V-ATPases cytoplasmic $\left(\mathrm{F}_{1}\right)$ and membrane $\left(\mathrm{F}_{0}\right)$ domains, each consists of several subunits (Harvey \& Nelson 1992). The subunit C, although not required for enzymatic activity under certain conditions (Puopolo et al.1992), appears to be important for the assembly of the $\mathrm{F}_{1}$ domain (Ho et al. 1993).

We have cloned a complete cDNA coding for the VATPase subunit $\mathrm{C}$ of the sand fly vector $L$. longipalpis. This full length cDNA clone was obtained by screening a midgut expression library with a previously identified DDRT-PCR fragment of approximately $220 \mathrm{bp}$ obtained from RNA of insects artificially infected with $L$. braziliensis (Ramalho-Ortigão et al. 2001). The complete cDNA codes for a 386 amino acid predicted protein with an estimated molecular weight of $40 \mathrm{kDa}$. The L. longipalpis V-ATPase (LIVATPase) shows a high degree of identity and similarity, based on amino acid comparison, with their counterparts from A. aegypti and $A$. gambiae, D. melanogaster, $M$. sexta. LIVATPase possesses three putative glycosylation sites, similar to what is predicted for A. americanum and M. sexta. In contrast, Drosophila V-ATPase subunit C appears to have four possible glycosylation sites (not shown).

The amino acid and phylogenetic analysis of V-ATPase subunit $\mathrm{C}$ from several insects demonstrated a wellconserved protein with a small polymorphic site at the $\mathrm{C}$ terminus. It is interesting to note that all Nematocera species analyzed in this study are blood-feeding insects with their V-ATPases displaying a considerable evolutionary distance from those of non-blood feeding insects. Such divergence of V-ATPase C from blood feeding to non-blood feeding insects may point to a link between blood feeding behavior and/or physiology and the molecular evolution of the V-ATPase C gene. 
Southern blot analysis indicates possibly only one copy of the V-ATPase subunit C gene in L. longipalpis similar to what was observed for M. sexta (Merzendorfer et al. 2000). In A. aegypti, although there is a single copy of the V-ATPase A subunit, the presence of more than one copy of the subunit $\mathrm{C}$ gene appears to be the case (Gill et al. 1998).

The expression of V-ATPase appears to be up-regulated in L. longipalpis after a blood meal. In the mosquito A. gambiae, the principal vector of human malaria, a midgut-specific V-ATPase, whose expression is apparently altered by blood feeding, has been identified (Dimopoulos et al. 1996). Analysis of V-ATPase subunit $\mathrm{C}$ expression throughout $L$. longipalpis development suggests a stage-specific regulation. While low level of expression was observed in eggs, larval stages L1 through L3, a high level of expression was seen in L4 stage larvae and pupae, approximately double of that seen in L1 larvae. These results are in contrast to what was detected for A. gambiae (Dimopoulos et al. 1996), where intermediate larval stages display the highest expression of V-ATPase, and a lower expression is seen in pupae. VATPase expression has also been shown in pupae and fourth instar larvae of $C$. quinquefasciatus, and the protein was detected in fourth instar larvae of both $C$. quinquefasciatus and A. aegypti (Filippova et al. 1998). However in these studies no data on the profile of VATPase expression of other developmental stages were obtained. Additionally, the expression of V-ATPase C is up-regulated in L. longipalpis following a blood meal, with levels approximately twice as high at $6 \mathrm{~h}$ after blood feeding, as compared to unfed females. Interestingly, the level of expression of this gene is approximately three times higher in males than females fed on sugar indicating an important physiological role for this molecule in L. longipalpis males.

In $L$. longipalpis, re-acidification of the midgut following digestion of a blood meal has been linked to metacyclogenesis of Leishmania within the sand fly (Gontijo et al. 1998). Before a blood meal, midgut $\mathrm{pH}$ was measured at approximately $\mathrm{pH} 6$ and the hindgut at a $\mathrm{pH}$ lower than $\mathrm{pH}$ 6. Upon taking a blood meal, $\mathrm{pH}$ in the gut increases as a result of the $\mathrm{pH} 7.4$ of blood. After complete digestion, $\mathrm{pH}$ may decrease to levels prior to the blood meal. Gontijo et al. (1998) proposed that the midgut reacidification would stimulate metacyclogenesis of Leishmania taken with an infective blood meal as seen with cultured parasites, where low $\mathrm{pH}$ induces metacyclogenesis (Zakai et al. 1998). A possible role for V-ATPases in events leading to metacyclogenesis of Leishmania remains to be elucidated.

\section{REFERENCES}

Anderson JM, Oliveira F, Kamhawi S, Mans BJ, Reynoso D, Seitz AE, Lawyer P, Garfield M, Pham M, Valenzuela JG 2006. Comparative salivary gland transcriptomics of sandfly vectors of visceral leishmaniasis. BMC Genomics 7: 52.

Antunes-Uchoa CM, Barrientos Serra CM, Duarte R, Magalhães CM, Silva RM, Theophilo F, Figliuolo LP, Horta FT, Madeira MF 2001. Serological and epidemiological aspects of canine American tegumentary leishmaniasis from Maricá, Rio de Janeiro, Brazil. Rev Soc Bras Med Trop 34: 563-568.
Bauzer LG, Souza NA, Maingon RD, Peixoto AA 2007. Lutzomyia longipalpis in Brazil: a complex or a single species? A minireview. Mem Inst Oswaldo Cruz 102: 1-12.

Charlab L, Valenzuela JG, Rowton RD, Ribeiro JMC 1999. Toward an understanding of the biochemical and pharmacological complexity of the saliva of a hematophagous sand fly Lutzomyia longipalpis. Proc Natl Acad Sci USA 96: 15155-15160.

Cociancich SO, Park SS, Fidock DA, Shahabuddin M 1999. Vesicular ATPase-overexpressing cells determine the distribution of malaria parasite oocysts on the midguts of mosquitoes. J Biol Chem 274: 12650-12655.

Dillon RJ, Ivens AC, Churcher C, Holroyd N, Quail MA, Rogers ME, Soares MB, Bonaldo MF, Casavant TL, Lehane MJ, Bates PA 2006. Analysis of ESTs from Lutzomyia longipalpis sand flies and their contribution toward understanding the insectparasite relationship. Genomics 88: 831-840.

Dimopoulos G, Richman A, della Torre A, Kafatos FC, Louis C 1996. Identification and characterization of differentially expressed cDNAs of the vector mosquito, Anopheles gambiae. Proc Natl Acad Sci USA 93: 13066-13071.

Filippova M, Ross LS, Gill SS 1998.Cloning of the V-ATPase B subunit cDNA from Culex quinquefasciatus and expression of the B and C subunits in mosquitoes Insect Mol Biol 7: 223-232.

Forgac M 1989. Structure and function of a vacuolar class of ATP-driven proton pumps. Physiol Rev 69: 765-798.

Gill SS, Chu PB, Smethurst P, Pietrantonio PV, Ross LS 1998. Isolation of the V-ATPase A and c subunit cDNAs from mosquito midgut and Malpighian tubules. Arch Insect Biochem Physiol 37: 80-90.

Gontijo CM, da Silva ES, de Fuccio MB, de Sousa MC, Pacheco RS, Dias ES, Andrade Filho JD, Brazil RP, Melo MN 2002. Epidemiological studies of an outbreak of cutaneous leishmaniasis in the Rio Jequitinhonha Valley, Minas Gerais, Brazil. Acta Trop 81: 143-150.

Gontijo NF, Almeida-Silva S, Costa FF, Mares-Guia ML, Williams P, Melo MN 1998. Lutzomyia longipalpis: $\mathrm{pH}$ in the gut, digestive glycosidases, and some speculations upon Leishmania development. Exp Parasitol 90: 212-219.

Han YS, Thompson J, Kafatos FC, Barillas-Mury C 2000. Molecular interactions between Anopheles stephensi midgut cells and Plasmodium berghei: the time bomb theory of ookinete invasion of mosquitoes. EMBO J 19: 6030-6040.

Harvey WR, Nelson N 1992. V-ATPases, The Company of Biologists Ltd., London.

Ho MN, Hill KJ, Lindorfer MA, Stevens TH 1993. Isolation of vacuolar membrane $\mathrm{H}(+)$-ATPase-deficient yeast mutants; the VMA5 and VMA4 genes are essential for assembly and activity of the vacuolar H(+)-ATPase J Biol Chem 268: 221-227.

Holt RA, Subramanian GM, Halpern A, Sutton GG, Charlab R, Nusskern DR, Wincker P, Clark AG, Ribeiro JM, Wides R, Salzberg SL, Loftus B, Yandell M, Majoros WH, Rusch DB, Lai Z, Kraft CL, Abril JF, Anthouard V, Arensburger P, Atkinson PW, Baden H, de Berardinis V, Baldwin D, Benes V, Biedler J, Blass C, Bolanos R, Boscus D, Barnstead M, Cai S, Center A, Chaturverdi K, Christophides GK, Chrystal MA, Clamp M, Cravchik A, Curwen V, Dana A, Delcher A, Dew I, Evans CA, Flanigan M, Grundschober-Freimoser A, Friedli L, Gu Z, Guan P, Guigo R, Hillenmeyer ME, Hladun SL, Hogan JR, Hong YS, Hoover J, Jaillon O, Ke Z, Kodira 
C, Kokoza E, Koutsos A, Letunic I, Levitsky A, Liang Y, Lin JJ, Lobo NF, Lopez JR, Malek JA, McIntosh TC, Meister S, Miller J, Mobarry C, Mongin E, Murphy SD, O’Brochta DA, Pfannkoch C, Qi R, Regier MA, Remington K, Shao H, Sharakhova MV, Sitter CD, Shetty J, Smith TJ, Strong R, Sun J, Thomasova D, Ton LQ, Topalis P, Tu Z, Unger MF, Walenz B, Wang A, Wang J, Wang M, Wang X, Woodford KJ, Wortman JR, Wu M, Yao A, Zdobnov EM, Zhang H, Zhao Q, Zhao S, Zhu SC, Zhimulev I, Coluzzi M, della Torre A, Roth CW, Louis C, Kalush F, Mural RJ, Myers EW, Adams MD, Smith HO, Broder S, Gardner MJ, Fraser CM, Birney E, Bork P, Brey PT, Venter JC, Weissenbach J, Kafatos FC, Collins FH, Hoffman SL 2002. The genome sequence of the malaria mosquito Anopheles gambiae. Science 298: 129-149.

Huang CG, Tsai KH, Wu WJ, Chen WJ 2006. Intestinal expression of $\mathrm{H}+\mathrm{V}$-ATPase in the mosquito Aedes albopictus is tightly associated with gregarine infection. $J$ Eukaryot Microbiol 53: 127-135.

Jäger D, Novak FJS, Harvey WR, Wieczorek H, Klein U 1996. Temporal and spatial distribution of V-ATPase and its mRNA in the midgut of the moulting Manduca sexta. J Exp Biol 199: 1019-1027.

Klein U 1992. The insect V-ATPase, a plasma membrane proton pump energizing secondary active transporting epithelia. J Exp Biol 172: 345-354.

Kumar S, Tamura K, Nei M 2004. MEGA3: integrated software for molecular evolutionary genetics analysis and sequence alignment. Brief Bioinform 5: 150-63.

Lainson R, Rangel EF 2005. Lutzomyia longipalpis and the ecoepidemiology of American visceral leishmaniasis, with particular reference to Brazil. Mem Inst Oswaldo Cruz 100: 811-827.

Marrelli MT, Moreira CK, Kelly D, Alphey L, Jacobs-Lorena M 2006. Mosquito transgenesis: what is the fitness cost? Trends Parasitol 22: 197-202.

Merzendorfer H, Graf R, Huss M, Harvey WR, Wieczorek H 1997. Regulation of proton-translocating V-ATPases. J Exp Biol 200: 225-235.

Merzendorfer H, Reineke S, Zhao XF, Jacobmeier B, Harvey
WR, Wieczorek H. 2000. The multigene family of the tobacco hornworm V-ATPase: novel subunits a, C, D, H, and putative isoforms. Biochim Biophys Acta 1467: 369-379.

Nelson N 2003. A journey from mammals to yeast with vacuolar H+-ATPase (V-ATPase). J Bioenerg Biomembr 35: 281-289.

Puopolo K, Sczekan M, Magner R, Forgac M 1992. The 40-kDa subunit enhances but is not required for activity of the coated vesicle proton pump. J Biol Chem 267: 5171-5176.

Ramalho-Ortigão JM, Traub-Cseko YM 2003. Molecular characterization of Llchit1, a midgut chitinase cDNA from the leishmaniasis vector Lutzomyia longipalpis. Insect Biochem Mol Biol 33: 279-287.

Ramalho-Ortigao JM, Kamhawi S, Joshi MB, Reynoso D, Lawyer PG, Dwyer DM, Sacks DL, Valenzuela JG 2005. Characterization of a blood activated chitinolytic system in the midgut of the sand fly vectors Lutzomyia longipalpis and Phlebotomus papatasi. Insect Mol Biol 14: 703-712.

Ramalho-Ortigão JM, Temporal P, de Oliveira SMP, Barbosa AF, Vilela ML, Rangel EF, Brazil RP, Traub-Cseko YM 2001. Characterization of constitutive and putative differentially expressed, mRNAs by means of ESTs, RT-PCR, and RAPD from the sand fly vector Lutzomyia longipalpis. Mem Inst Oswaldo Cruz 96: 105-111.

Sambrook J, Fritsch EF, Maniatis T 1989. Molecular Cloning: A Laboratory Manual, Cold Spring Harbor Laboratory Press, Cold Spring Harbor, NY.

Weng XH, Huss M, Wieczorek H, Beyenbach KW 2003. The Vtype $\mathrm{H}^{+}$-ATPase in Malpighian tubules of Aedes aegypti: localization and activity. J Exp Biol 206: 2211-2219.

Wieczorek H, Grüber G, Harvey WR, Huss M, Merzendorfer $\mathrm{H}$ and Zeiske W 2000. Structure and regulation of insect plasma membrane H+-V-ATPase. J Exp Biol 203: 127-135.

Zakai HA, Chance ML, Bates PA 1998. In vitro stimulation of metacyclogenesis in Leishmania braziliensis, L. donovani, L. major and L. mexicana. Parasitology 116: 305-309.

Zhuang Z, Linser PJ, Harvey WR 1999. Antibody to H(+) VATPase subunit E colocalizes with portasomes in alkaline larval midgut of a freshwater mosquito (Aedes aegypti). $J$ Exp Biol 202: 2449-2460. 
